\title{
Micro-analytical Investigations on Actinide (Am, Cm) Reference Materials
}

\author{
Xenia Ritter ${ }^{1,2}$, Philipp Pöml ${ }^{1}$, Stephane Brémier ${ }^{1}$, Jasper Berndt ${ }^{2}$ \\ 1 European Commission, Joint Research Centre, Institute for Transuranium Elements, P.O. Box 2340, \\ 76125 Karlsruhe, Germany \\ 2. Institut für Mineralogie, Westfälische Wilhelms-Universität, Corrensstr. 24, 48149 Münster, Germany
}

Electron probe micro-analysis (EPMA) is an important method for a broad range of applications in nuclear sciences. One main target is to improve the safety of the nuclear fuel cycle, by studying the chemical and physical properties of spent nuclear fuel and its fission products, either solid, volatiles, or gases, after the irradiation (post-irradiation examinations) [1].

As in every other micro-analytical method, quantification of elements can only be achieved when the new sample is referenced to a sample of known concentration (i.e., a standard). In this paper we investigate the options to prepare and use reference materials for the actinides Am and Cm.

Actinides are extremely toxic and highly radioactive (especially the transuranic elements) hence difficult to handle. Two Am oxide compounds are currently investigated in the shielded facilities of the Institute for Transuranium Elements (ITU): $\left(\mathrm{U}_{0.9} \mathrm{Am}_{0.1}\right) \mathrm{O} 2$ and $\left(\mathrm{U}_{0.8} \mathrm{Am}_{0.2}\right) \mathrm{O} 2$. These ceramics are being characterized by inductively coupled plasma mass spectrometry (ICP-MS) for their bulk chemistry and impurities, by EPMA (Cameca SX100R) for their precise chemical composition and lateral homogeneity, and by secondary mass spectrometry (SIMS) (Cameca 6fR) depth-profiling for their in-depth homogeneity. The Am content of the two compounds is cross-checked by EPMA by analytical determination and using a calibration-curve approach described in [2]: the X-ray Ma and $M \beta$ intensities of Th, U, Np, and Pu are measured, and the resulting curve fitted. The Am intensity can then be linked to the $U$ intensity; this allows using the $U$ signal as a standard for Am. Both the analytical characterization and the calibration curve method are expected to yield the same result.

The resulting new Am standard can then be used not only to measure Am in nuclear fuels, but also to:

- accurately measure and monitor the Am content of ITU's $\mathrm{PuO}_{2}$ standard. Future $\mathrm{Pu}$ measurements will highly benefit from a better characterized $\mathrm{PuO} 2$ standard;

- determine a correction factor for the measurement of $\mathrm{Cm}$ in nuclear fuels.

It is extremely inconvenient to manufacture or handle a Cm standard for EPMA as a dedicated facility with special shielding would have to be made available to host the element and prepare its compounds. Thus, the correction factor approach is used for the measurement of $\mathrm{Cm}$. To this end, a calibration curve is measured for the elements Th, $\mathrm{U}, \mathrm{Np}, \mathrm{Pu}$, and Am which is then extrapolated to $\mathrm{Cm}$. Similarly to the case of the calibration-curve approach for Am, the $\mathrm{Cm}$ intensity is linked to the intensity of $\mathrm{U}$, which can then be used as a standard for $\mathrm{Cm}$. 
The availability of the new Am standard and Cm correction factor will open new opportunities for the micro-analytical work on the safety of the nuclear fuel cycle. Among the first applications foreseen at ITU it is worth mentioning the EPMA studies on metallic fast reactor fuels containing minor actinides and other projects related to the investigation of safety and effectiveness of closed nuclear fuel cycles including minor actinide transmutation.

\section{References:}

[1] Walker, C., Journal of Analytical Atomic Spectrometry 14 (1999), p. 447.

[2] Pöml, P. Brémier, S., Laheurte, F., Hasnaoui, R. and Walker, C. T., IOP Conf. Series:

Materials Science and Engineering 7 (2010), doi: 10.1088/1757-899X/7/1/012025

[3] Brémier, S., Inagaki, K., Pöml, P., Capriotti, L., Papaioannou, D., Rondinella, V.V., Ohta, H., Ogata, T., Proc. ANS Winter Conf. 2013. Nov 10-14, Washington DC, USA. 